\title{
Partitioning of polybrominated biphenyl ethers from mother to fetus and potential health-related implications
}

\author{
Mei-Yun Zheng b, ${ }^{\text {, }}$ Xing-Hong Li ${ }^{\text {a, }}{ }^{*}, 1$, Yun Zhang ${ }^{\text {a, c }}$, You-Lin Yang ${ }^{\text {b }}$, Wen-Yue Wang ${ }^{\text {a, c }}$ \\ Yuan $\operatorname{Tian}^{\mathrm{c}}$ \\ a State Key Laboratory of Environmental Chemistry and Ecotoxicology, Research Center of Eco-Environment Sciences, Chinese Academy of Sciences, P.O. Box \\ 2871, 18 Shuangqing Road, Haidian District, Beijing, 100085, People's Republic of China \\ ${ }^{\mathrm{b}}$ The First People's Hospital of Wenling, Taizhou, 317004, Zhejiang Province, People's Republic of China \\ ${ }^{\mathrm{c}}$ Beijing Technology and Business University, Beijing, 100037, People's Republic of China
}

\section{H I G H L I G H T S}

- The expectant women living in e-waste recycling area might be highly exposed to PBDEs.

- The placenta could effectively hinder the transfer of PBDEs from mother to fetus.

- Higher-brominated BDEs transfer was hindered more by placenta, but they did not remain in more amounts in it.

- The concentration of BDE congeners among the paired samples could be fitted by equations.

- There was a significant association between BDEs and $\mathrm{TT}_{4}$ levels in maternal serum.

\section{A R T I C L E I N F O}

\section{Article history:}

Received 23 September 2016

Received in revised form 23 November 2016

Accepted 27 November 2016

Available online 10 December 2016

Handling Editor: Myrto Petreas

\section{Keywords:}

PBDEs

Transplacental transfer

THs implication

E-waste

\begin{abstract}
A B S T R A C T
Presently, knowledge on the partitioning of polybrominated biphenyl ethers (PBDEs) from mother to fetus and the relationship between PBDE exposure and the levels of thyroid hormones (THs) needs to be extended further. In the present study, we investigated the concentrations of PBDEs in paired mother -fetus samples from 72 pregnant women in Wenling, China. The detection of PBDE concentration suggested that the expectant women living in Wenling for over 20 years might be highly exposed to PBDEs, which is largely ascribed to e-waste recycling activities in the local environment. The median concentration ratios between paired cord serum and maternal serum for higher-brominated BDEs were smaller than those for lower-brominated BDEs $(p<0.05)$. This result indicated that the placenta could hinder the transfer of PBDEs from mother to fetus, and the hindrance effect increased with higherbrominated congeners. Median ratios of paired placenta vs. maternal serum concentrations varied in a narrow range $(0.15-0.25)$, with significantly lower value for BDE-209 than that for BDE-28 $(p<0.01)$. The extent of transplacental transfer was larger than that of placental retention for eight BDE congeners $(p<0.01)$. The concentration of BDE congeners among the paired samples could be fitted by equations, implying that their distribution could be predicted for each other $(p<0.001)$. There was a significant association between BDE-153 and $\mathrm{TT}_{4}$ levels in maternal serum from Wenling local residents $(p<0.05)$, suggesting potential implications for fetal development and their mothers' health in e-waste recycling environment. In addition, it was found that the relationship between BDEs and TH levels was likely affected by the exposure duration of the population to PBDEs.
\end{abstract}

๑) 2016 Published by Elsevier Ltd.

\section{Introduction}

Polybrominated biphenyl ethers (PBDEs) are a group of

\footnotetext{
* Corresponding author.

E-mail address: lxhzpb@rcees.ac.cn (X.-H. Li).

1 Authors have equal contribution.
}

chemicals with 209 congeners and are widely used as flame retardants in commercial products. PBDEs have POPs characteristic, leading to ubiquitous exposure to humans and wildlife (Lyche et al., 2015). Even though stringent worldwide regulations have been adopted since the early 21 st century, the PBDE-containing products are still in use for a long time. Therefore, it is expected that the continued release from the currently in-use and gradually 
abandoned PBDE-containing products will cause environmental contamination for a prolonged period in the future.

The transplacental transfer of BDE congeners has been proved consistently, and the extent of PBDE transfer across the placenta had been assessed roughly by the median values of concentration ratios between maternal blood and cord blood in the published literature (Meijer et al., 2008; Frederiksen et al., 2010; Jakobsson et al., 2012; Chen et al., 2013; Li et al., 2013; Zhao et al., 2013; Choi et al., 2014; Vizcaino et al., 2014). However, these ratios obtained in most studies have to be considered with caution because of the lack of transparency, including sample size, timing of sampling, statistical analysis with paired data, and so on, which did not allow proper quantification of the mother to child transfer (Jakobsson et al., 2012). To our knowledge, a mathematical model describing the partitioning relationship of PBDEs from mother to fetus is thus far unavailable.

Animal experiments have proved that PBDEs may be characterized as thyroid hormone (TH) disruptors (Talsness, 2008). In humans, because maternal THs substantially affect fetal neurodevelopment (Haddow et al., 1999), the relationship between prenatal exposure to PBDEs and serum TH levels has raised specific concern. However, previous studies have drawn controversial conclusions. Some studies did not find any association between PBDE exposure and TH levels, whereas other studies found certain correlations-yet the relationship was not definite for specific congener and specific TH (Czerska et al., 2013). Nevertheless, these antecedents, on the one hand, suggested the potential effect of PBDE exposure on the THs levels in humans, and on the other hand, they called for more sound and thorough work to understand the hidden relationship between PBDE exposure and TH levels during women's pregnancy because of the importance of THs in the early development of fetus.

The main purpose of this study was to quantify the partitioning of specific BDE congeners from mother into fetus through paired maternal serum, placental tissue, and cord serum collected simultaneously from the same women and explore the possible effect of PBDE exposure on maternal THs levels. The obtained result was helpful to understand the migration/transformation behaviors of PBDE and health effects of exposure to PBDEs in humans.

\section{Materials and methods}

\subsection{Sample collection}

The information on sample collection and sampling location had been described in two published studies (Ben et al., 2014; Lv et al., 2015). In brief, Taizhou is one of two largest e-waste recycling regions in China, while Wenling is one of two major cities executing the e-waste recycling activities in the Taizhou region. In total, in 2010-2011, 72 paired samples (including maternal blood, umbilical cord blood, and placenta) were collected from local hospital in Wenling, Taizhou, China. The donors could be classified as $R_{20}$ group $(n=48)$ and $R_{3}$ group $(n=24)$. The donors in the $R_{20}$ group $(\mathrm{n}=48)$ were living or had recently lived in Wenling villages for more than 20 years, where e-waste recycling activities were undertaken, but did not directly participate in such activities. The donors in the $\mathrm{R}_{3}$ group $(\mathrm{n}=24)$ who had lived in Wenling for less than 3 years had not previously lived in villages where e-waste recycling activities were undertaken. After signing the informed consent, the donor's personal information was obtained through a questionnaire.

\subsection{Sample extraction, clean-up, and analysis}

The samples ( $5 \mathrm{~mL}$ for maternal serum, $10 \mathrm{~mL}$ for cord serum, and $2.0 \mathrm{~g}$ dry weight for placenta) were extracted and cleaned up following a previous procedure (Lv et al., 2015). In brief, both BDE77 and ${ }^{13} \mathrm{C}$-BDE-209, as the internal standard, were spiked into the serum or placenta sample before the extraction. Then, serum samples were denatured with $\mathrm{HCl}$ and isopropanol and ultrasonically extracted by the mixture solution of methyltert-butyl ether (MtBE) and hexane (Hex) with three times repeats. The combined extracts were washed with $\mathrm{KCl}$ solution, dried with $\mathrm{Na}_{2} \mathrm{SO}_{4}$, and then concentrated. Placenta samples were extracted ultrasonically three times with the mixture solution of MtBE, Hex, and dichloromethane with three times repeats, and then dried and concentrated. The concentrated extract for serum or placenta was cleaned up in a multilayer sulfuric acid silica gel column. The final elute of either placenta or serum was concentrated to $20-50 \mu \mathrm{L}$, and the known amount of the injection internal standard (BDE166) was added before the GC/MS analysis.

PBDEs compounds were analyzed by Agilent 6890GC, coupled with 5973MSD. The MS performed in a negative ion chemical ionization and selected ion mode. The separation was performed using a RTX-1614 fused silica capillary column (0.25-mm ID and $0.1-\mu \mathrm{m}$ film thickness; J\&W Scientific, Folsom, CA, USA) with 30-m length for BDE-28, BDE-47, BDE-99, BDE-100, BDE-153, BDE-154, and BDE-183, and 15-m length for BDE-209. The GC oven temperature was programmed as follows: maintaining the initial temperature $100{ }^{\circ} \mathrm{C}$ for $2 \mathrm{~min}$; increased to $250{ }^{\circ} \mathrm{C}$ at a rate of $25{ }^{\circ} \mathrm{C}$ $\min ^{-1}$; ramped from $250{ }^{\circ} \mathrm{C}$ to $260^{\circ} \mathrm{C}$ at a rate of $1.5^{\circ} \mathrm{C} \mathrm{min}{ }^{-1}$; and then heated up to high temperature of $310^{\circ} \mathrm{C}$ at a rate of $25^{\circ} \mathrm{C}$ $\mathrm{min}^{-1}$, which was held for $27 \mathrm{~min}$. The carrier gas used was high purity helium $(\geq 99.9995 \%)$ with a flow rate of $1.0{ }^{\circ} \mathrm{C} \mathrm{min}{ }^{-1}$, and methane was used as the reaction gas. Samples were injected in the splitless mode, and the injection volume was $1.0 \mu \mathrm{L}$. The injector, transfer line, and ion source temperatures were $150{ }^{\circ} \mathrm{C}, 150{ }^{\circ} \mathrm{C}$, and $320^{\circ} \mathrm{C}$, respectively. The ion fragments monitored were $\mathrm{m} / \mathrm{z} 79$ and 81 for the tri-to octa-BDE congeners, $m / z 488.7$ and 486.7 for BDE209, and $\mathrm{m} / \mathrm{z} 492.7$ and 494.7 for ${ }^{13} \mathrm{C}_{12}$-labeled BDE-209.

Lipids in placenta tissue extracts were determined by a gravimetric method, and a colorimetric method based on the sulfo-phospho-vanillin reaction was used to determine the lipids in the serum samples (Phillips et al, 1989). The levels of THs, including thyroid stimulating hormone (TSH), total triiodothyronine $\left(\mathrm{TT}_{3}\right)$, total thyroxine $\left(\mathrm{TT}_{4}\right)$, free triiodothyronine $\left(\mathrm{FT}_{3}\right)$, and free thyroxine $\left(\mathrm{FT}_{4}\right)$, were obtained in the maternal serum samples using a chemiluminescent microparticle immunoassay at a local hospital. The personal information of donors and their infants, and TH levels in the maternal serum from 66 donors had been reported in a previous study (Ben et al., 2014), and are listed in Tables SI-1 and SI2 of supporting information, respectively.

\subsection{Quality control}

The recoveries of the surrogate standards that were spiked into the samples before the extraction were $77-109 \%$ for $\mathrm{BDE}-77$ and $61-80 \%$ for ${ }^{13} \mathrm{C}-\mathrm{BDE}-209$ in the maternal serum, $75-110 \%$ and $60-85 \%$ in the cord serum, and $72-107 \%$ and $68-89 \%$ in the placenta, respectively. Bovine serum and fetal bovine serum, and olive oil $(0.1 \mathrm{~g})$ were used to represent the method blank of serum and placenta, respectively. Seven replicates of method blank spiked with the mixture of target analytes were processed through the entire extraction procedure and analyzed. The method detection limits (MDLs) were defined as the mean plus three standard deviations of values associated with the analysis. On the basis of the maternal serum $(5.0 \mathrm{~mL})$, the cord serum volume $(10.0 \mathrm{~mL})$, dry weight of the placenta samples $(2.0 \mathrm{~g})$, average lipid concentration (6.4 $\mathrm{g} \mathrm{L}^{-1}$ for the maternal serum, $2.3 \mathrm{~g} \mathrm{~L}^{-1}$ for the cord serum and $6.24 \%$ for the dried placenta), and injection volume ( $50 \mu \mathrm{L}$ for the 
maternal serum and the placenta, and $20 \mu \mathrm{L}$ for the cord serum), the MDLs were $150-720 \mathrm{pg} \mathrm{g}^{-1}$ lipid weight (lw) in the maternal serum, 90-440 $\mathrm{pg} \mathrm{g}^{-1} \mathrm{lw}$ in the cord serum, and $40-220 \mathrm{pg} \mathrm{g}^{-1} \mathrm{lw}$ in the placenta, respectively. Analyte values were corrected for the recovery of the internal standards.

\subsection{Statistical analysis}

All statistical analyses were performed using SPSS 22.0 software (SPSS Inc., Chicago, IL, USA), and least-squares linear regressions were fitted using OriginPro8 SR0 software (www.OriginLab.com). The Kolmogorove-Smirnov test was used to examine the continuous variables for the normal distribution. The independent samples $t$ test (Mann-Whitney $U$ test) was used to test for the differences in BDE levels between the $R_{20}$ and the $R_{3}$ groups and for the ratios of cord serum vs. maternal serum concentrations ( $\mathrm{F} / \mathrm{M}$ ratio) and placenta vs. maternal serum concentrations ( $\mathrm{P} / \mathrm{M}$ ratios) between the two groups. The Kruskal-Wallis $\mathrm{H}$ test was used to detect differences in the extent of the placental transfer ( $\mathrm{F} / \mathrm{M}$ ratio) among eight BDE congeners and the extent of placental retention $(\mathrm{P} / \mathrm{M}$ ratios). The Spearman correlation analysis was conducted for exploring the relationship related to the extent of the placental transfer and log octanol-water partition coefficient $\left(K_{o w}\right)$ for eight BDE congeners, and lipid-adjusted BDE concentrations among tissues. Analysis of the potential relationship between logtransformed PBDE concentrations and log-transformed THs levels was conducted using the Pearson correlation, the partial correlation method, and the linear regression model. The distribution model of BDE congeners among maternal serum, placental tissue, and cord serum was fitted by the least-squares linear regressions. The levels of compounds with <MDLs were assigned the value 1/2 MDLs for statistical description of PBDEs, and were not used when calculating the concentration ratios among tissues and for fitting the linear equation. A $p<0.05$ was considered to represent statistical significance.

\section{Results and discussion}

\subsection{BDE levels}

In this study, eight BDE congeners, including BDE-28, -47, -99 , $-100,-153,-154,-183$, and -209 , were detected in the 72 paired maternal serum, umbilical cord serum, and placental tissue collected from Chinese pregnant women living in Wenling, Taizhou. In the $\mathrm{R}_{20}$ group, the median concentration of the total PBDEs was $19.3 \mathrm{ng} \mathrm{g}^{-1} \mathrm{lw}$ in the maternal serum, $6.84 \mathrm{ng} \mathrm{g}^{-1} \mathrm{lw}$ in the umbilical cord serum, and $2.20 \mathrm{ng} \mathrm{g}^{-1} \mathrm{lw}$ in the placental tissue, while in the $R_{3}$ group, the median concentration $8.13 \mathrm{ng} \mathrm{g}^{-1} \mathrm{lw}$, $4.47 \mathrm{ng} \mathrm{g}^{-1} \mathrm{lw}$ and $1.06 \mathrm{ng} \mathrm{g}^{-1} \mathrm{lw}$, respectively. Regardless of matrixes, the two independent samples $t$-test (Mann-Whitney U) showed that the concentrations of the total PBDEs in the $\mathrm{R}_{20}$ group were significantly higher than those in the $\mathrm{R}_{3}$ group $(p<0.05$, Fig. 1 and Tables SI-3). Accordingly, PBDE concentrations based on the wet-weight basis are also listed in Tables SI-4.

A few studies have reported the PBDE levels in the maternal blood, cord blood, and placenta from pregnant women and their babies in the other countries/regions, as listed in Tables SI-5. Although the numbers of BDE congeners detected were somewhat different in the published literature, eight major congeners, including BDE-28, -47, -100, -99, -154, -153, -183, and -209, have been detected in most reports (Tables SI-5). In general, the median levels of the total PBDEs in the maternal serum in the general population living in the USA and Canada varied in dozens $\mathrm{ng} \mathrm{g}^{-1} \mathrm{lw}$. However, except for the USA and Canada, the median levels in the other countries or regions, including the developed countries in western Europe and Asia, and Taiwan and Mainland China, were generally close to or less than $10 \mathrm{ng} \mathrm{g}^{-1} \mathrm{lw}$. For the $\mathrm{R}_{3}$ group population in this study, PBDE levels in the maternal serum were in the range of those found for the general pregnant women in most countries or regions around the world, excluding the USA and Canada. For the $\mathrm{R}_{20}$ group, the PBDE levels were $2-3$ times lower than those in the USA and Canada, but were over twofold higher than those in most countries or regions around the world, and those in the general pregnant women from Mainland China. Although the population in the $\mathrm{R}_{20}$ group was not directly involved in e-waste dismantling activities, they lived in the e-waste dismantling village and could be affected by such activities, likely resulting in the higher serum $\mathrm{BDE}$ levels relative to the general population.

With regard to cord serum, the PBDE levels in the pregnant women in most of the developed countries in western Europe and in Japan, Korean, and Taiwan were generally several $\mathrm{ng} \mathrm{g}^{-1} \mathrm{lw}$. The PBDE levels in our population were within the range of these developed countries/regions, with the values in the $\mathrm{R}_{20}$ group at the top and those in the $\mathrm{R}_{3}$ group at the bottom. Compared with the population in the other regions of Mainland China, the PBDE median level in the $\mathrm{R}_{20}$ group was close to the value assessed from the general population from the areas with high degree of industrialization in South China (5-10 $\mathrm{ng} \mathrm{g}^{-1} \mathrm{lw}$ ). The median level in the $\mathrm{R}_{3}$ group in this study was similar to that in the general metropolitans (Guangzhou City, $3.9 \mathrm{ng} \mathrm{g}^{-1} \mathrm{lw}$ ).

As listed in Tables SI-5, there are limited reports on PBDEs in human placental tissues. The PBDE median levels in the general population were $2.80 \mathrm{ng} \mathrm{g}^{-1} \mathrm{lw}$ in Denmark and $1.9 \mathrm{ng} \mathrm{g}^{-1} \mathrm{lw}$ in Spain, which were slightly higher than that in the $\mathrm{R}_{20}$ group in this study. In a previous report, the PBDE level found in the placenta from the women with unwanted pregnancies living in the surrounding area of e-waste recycling sites in Wenling (approximately $5.55 \mathrm{ng} \mathrm{g}^{-1} \mathrm{lw}$ when excluding BDE-197) was twofold higher than the value reported in the $R_{20}$ group in this study (Zhao et al., 2013). The donors in Zhao et al. (2013) and our studies were from the same region (Wenling) and were classified as nonoccupational exposure population with the similar sampling years. However, the placental tissue was collected in the first trimester in pregnancy in Zhao et al.'s report, and at delivery in our study, which may lead to the difference of PBDE levels in the two studies.

In short, this comparison result showed that the pregnant women and their fetuses living in the e-waste recycling area were exposed to the relatively higher PBDE levels than the general women from other regions around the world. Considering that fetal development was especially sensitive to PBDE levels, it is worth paying close attention to the potential health risk of pregnant women and their babies due to PBDE exposure from e-waste recycling activities.

\subsection{PBDE congener profiles}

The congener pattern of PBDEs in the maternal serum, cord serum, and placental tissue is shown in Fig. 2. Regardless of the group and matrix, both BDE-209 and BDE-153 were two major congeners, followed by BDE-47 or BDE-183. It was not surprising to find this predominance because both BDE-209 and BDE-153 were the most abundant congeners in the local environmental and biotic samples in Wenling, China, as reported by Zhao et al. (2013). The predominance of BDE-153 was also likely accounted for by its long half-life time in biota (Geyer et al., 2004; Thuresson et al., 2006). As BDE-209 has a short half-life of 15 days (Thuresson et al., 2006), its predominance implied that this population was recently and/or continuously exposed to BDE-209 (Huang et al., 2014). It was notable that the percentage of BDE-209 in serum from general Chinese 
population was approximately 77\% in Shanxi (Huang et al., 2014) (recalculated by the median value of eight BDE congeners in the literature), ascribing to the dominant market demand for deca-BDE technical products in the Northern China. The percentage in this study ( $41 \%$ for the exposure group and $34 \%$ for the control group) was approximately half of the result in Shanxi, China. The e-wastes recycled in Taizhou (including Wenling) primarily originate from European countries, Japan, the USA, and Russia, where large amount of penta- and octa-BDE technical products are used. The lower BDE209 profiles in this study, relative to the general population in Shanxi, were likely attributable to more products containing mixed BDE technical formulations recycled as e-waste in Wenling.

\subsection{Transplacental transfer}

The detection of PBDEs in cord serum indicated their transplacental transfer into the fetus, consistent with the published reports (Tables SI-5). The extent of transplacental transfer can be estimated by the $\mathrm{F} / \mathrm{M}$ ratio, defined as the ratio of the lipid-adjusted concentrations in the cord serum (F) and the maternal serum (M) (Meijer et al., 2008; Frederiksen et al., 2010; Jakobsson et al., 2012; Chen et al., 2013; Zhao et al., 2013; Vizcaino et al., 2014). The higher the $\mathrm{F} / \mathrm{M}$ ratio, the easier is the transfer of the compound.

In this study, ratio calculations for BDE congeners included only data from individuals who had both maternal serum and cord serum samples concentrations above MDLs. The two independent samples $t$-test (Mann-Whitney $U$ ) showed that there were no differences in the $\mathrm{F} / \mathrm{M}$ ratios for BDE congeners between the $\mathrm{R}_{20}$ group and the $\mathrm{R}_{3}$ group ( $p>0.05$ ); thus, the ratios for the two groups were combined for further data set discussion. After combining the data sets from the two groups, the median values and 25 th -75 th percentile ranges of the $\mathrm{F} / \mathrm{M}$ ratios, calculated by the individual pairs, are listed in Table 1 . Although the 75 th percentile values of the $F / M$ ratios $\geq 1$ were found for BDE-28, -47 , and -99 , the median ratios for eight BDE congeners were close to or less than 1, varying from 0.40 (BDE-183) to 0.84 (BDE-47). Between 2009 and 2011, Zhao et al. (2013) collected aborted human fetuses and placentas (10- to 13-week gestation) and maternal whole blood samples from healthy pregnant women living in the same region as that in our study (Wenling, Taizhou, China). In 31 paired aborted fetus and maternal whole blood samples, the F/M (aborted fetus against maternal whole blood) median ratio was less than 1 (approximately 0.35 for BDE-28, 0.25 for BDE-47, 0.3 for BDE-99, 0.1 for BDE-153, and 0.23 for BDE-209, estimated on the basis of data in Fig. 2 in Zhao et al.' report). Our result together with that from Zhao

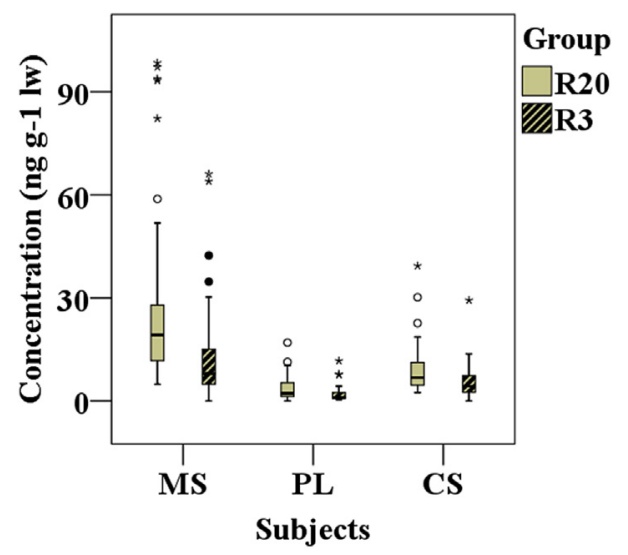

Fig. 1. Box plots of concentration of total PBDEs in maternal serum, paired placental tissue, and cord serum from women living in Wenling. MS: maternal serum; PL: placenta; CS: cord serum. et al.'s report indicated the restricted transfer for most BDE congeners, whether at early or late pregnancy, when these compounds crossed the placenta into fetus.

Furthermore, in this study, the lipid-adjusted F/M ratios of some BDE congeners significantly differed $(p<0.01$, Kruskal-Wallis $\mathrm{H}$ test), with the trend decreasing with the degree of bromination (Table 1). Statistical analysis (Spearman correlation analysis) showed a negative association between the $\mathrm{F} / \mathrm{M}$ median ratios and log octanol-water partition coefficient (Kow) for eight BDE congeners $(r=-0.833, p=0.01)$, which indicated the Kow value might largely affect the transfer of PBDEs from mother to fetus. Similarly, the $\mathrm{F} / \mathrm{M}$ median ratios were also significantly negatively correlated with the number of bromine substitutes and molecular weight ( $p<0.05$ for each, Spearman correlation analysis). Takahashi and Oishi (2000) proposed that the placental transfer of lipophilic chemicals with $\log$ Kow $>5$ might be limited or slow. Myren et al. (2007) found that some membranes are a barrier for the transport of compounds with molecular weight above $600 \mathrm{Da}$. For PBDEs, the log Kow values for eight studied congeners are over 5 (5.94-9.87), and the molecular weights are close to 600 Da for penta-brominated congeners (564.7 Da) and higher for hexa-to deca-brominated congeners. Therefore, it was not surprising to find the restricted transplacental transfer for most BDE congeners. In addition, relative to lower-brominated congeners, BDE-209 levels in serum might reflect the exposure toward the end of pregnancy more because of its short half-life (Jakobsson et al., 2012). The differences of half-lives were also likely to a factor affecting the $\mathrm{F} / \mathrm{M}$ ratios of BDE congeners.

The lipid-adjusted F/M ratios of PBDEs in the published literature were listed in Table 2 . To date, it could be seen that no data on the lipid-adjusted F/M ratio for BDE-183 could be obtained, and the result from this study timely filled the gap. Moreover, for tri-to hexabrominated BDEs, the $\mathrm{F} / \mathrm{M}$ ratios in this study generally showed relatively lower values than those reported in listed published literature. Nevertheless, if data from Chen et al.'s report in Table 2 were excluded, the ratio discrepancies for individual congener between our value and other values listed were limited within the scope of two times. However, in a pilot study on USA pregnant women (Chen et al., 2013), though the fetus-maternal ratio for BDE153 agreed with our result, those for BDE-28, $-47,-99,-100$, and -154 , presented much higher value. Chen et al. (2013) were puzzled with regard to the large difference in $\mathrm{F} / \mathrm{M}$ ratios observed between $\mathrm{BDE}$ 153 and other BDE congeners. The F/M ratio of BDE-153 demonstrated a similar pattern in all the listed reports (Table 2). Furthermore, relative to the low- or moderately brominated BDEs, the lipidadjusted F/M ratio of BDE-209 showed larger discrepancy in the published literature (Table 2). The ratio was 0.55 (this study), 0.50 (Jakobsson et al., 2012), 1.6 (Vizcaino et al., 2014), and 2.88 (Chen et al., 2013) in different reports, with 3- to 6-fold diversity. Because of the short elimination half-life, the serum level of BDE209 in inter-individuals might vary over days, weeks, and even months, and the simultaneous sampling for serum samples is therefore crucial for calculating the F/M ratio of BDE-209 (Jakobsson et al., 2012). The maternal serum and cord serum were collected with approximately 8-month intervals in Vizcaino et al.'s study (2014), whereas both were collected simultaneously at delivery in our study, Jakobsson et al.'s study (2012), and Chen et al.'s study (2013). Compared to our result, the difference in the time window of sampling for matched samples, might partly account for the ratio difference in Vizcaino et al.'s study (2014), but this could not explain the ratio diversity in Chen et al.'s study (2013). In addition to BDE-209, fetus-maternal ratios for other BDE congeners (BDE-153 excluded) were also different in Chen et al.'s study (2013).

The restricted transfer of most BDE congeners from mother to fetus and physicochemical properties-related mechanism could be 

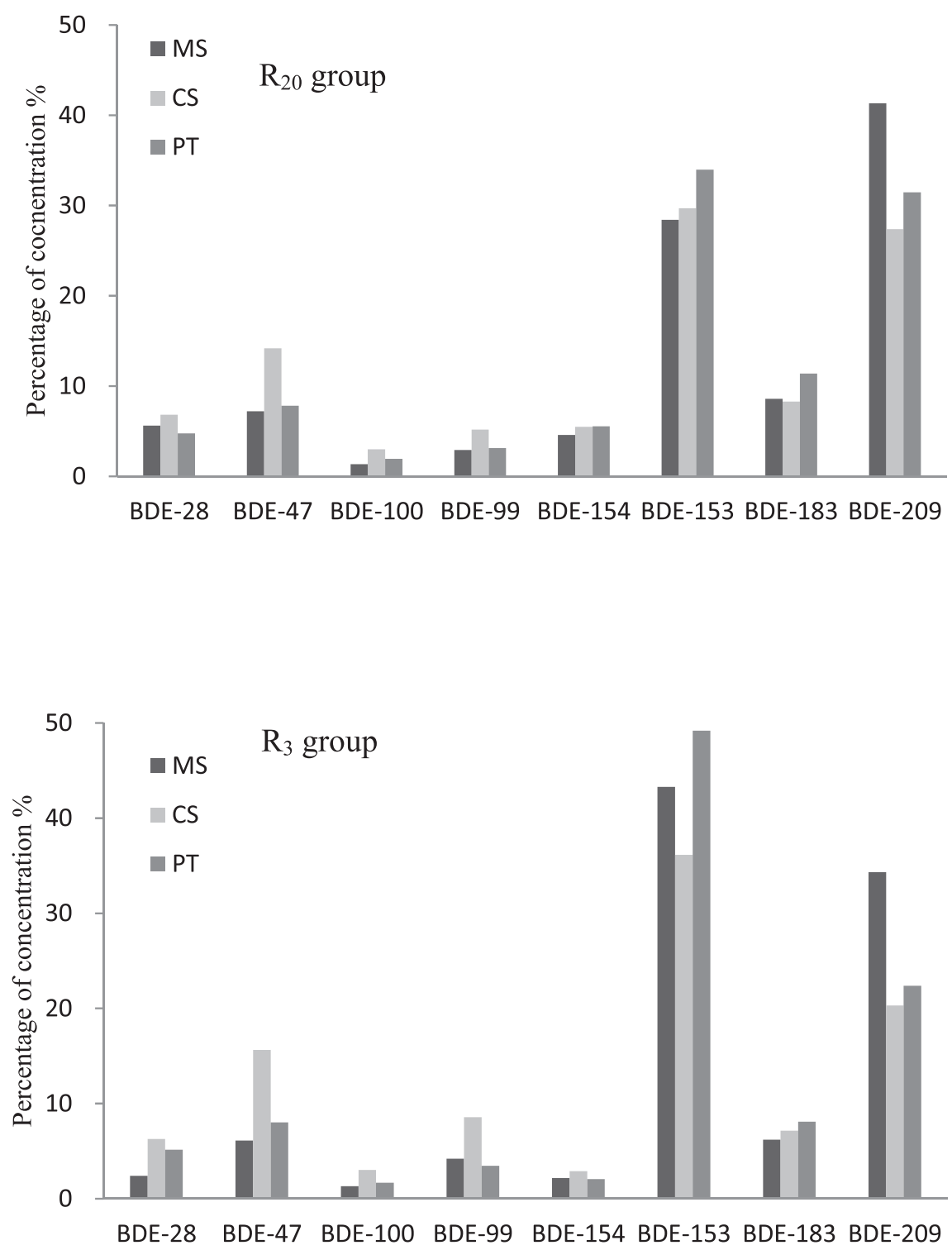

Fig. 2. Profiles of BDE congeners in maternal blood, cord blood, and placenta.

proved by this study and some previous reports (Frederiksen et al., 2010; Kim et al., 2012; Zhao et al., 2013). However, several studies also reported conflicting results (Chen et al., 2013; Vizcaino et al., 2014), as mentioned above. Some other processes such as the lower metabolic capacities to toxicants in fetus (Choi et al., 2014; Vizcaino et al., 2014), the redistribution of lipids from mother to fetus in the last trimester of pregnancy (Foster et al., 2011), and the transport mechanism related to certain active receptors or transporters (Kim et al., 2015) were suspected to affect the distribution of these pollutants between mother, placenta, and fetus. Nyholm et al. (2008) reported a dose-dependent maternal transfer in zebrafish (Danio rerio) exposed to PBDEs and several other brominated flame retardants. This finding reminds that chemical levels might also influence the transplacental transfer of PBDEs in humans. Further research was required to define and determine the role mechanisms related to this transplacental transfer of PBDEs.

\subsection{Placental retention}

PBDEs were detected in the placental tissue indicating that these compounds could be retained in the placenta. The degree of placental retention was estimated by the $\mathrm{P} / \mathrm{M}$ ratio, defined as the ratio of the lipid-adjusted concentrations in the placenta $(\mathrm{P})$ and the maternal serum (M). The higher the $\mathrm{P} / \mathrm{M}$ ratio, the larger was the extent to which the compound was retained in the placenta. The $\mathrm{P} / \mathrm{M}$ median ratios in this study varied from 0.15 to 0.25 for eight BDE congeners (Table 1), indicating that only $<30 \%$ BDE congeners in the maternal serum could be retained in the placental tissues.

The $\mathrm{P} / \mathrm{M}$ ratio calculated in Vizcaino et al.' study (2014) was 0.31 for BDE-153 and 0.23 for BDE-209, which were slightly higher than our results. In addition, Zhao et al. (2013) found that the P/B ratios (placenta vs. matched whole blood) for BDE-28, BDE-99, and BDE47 were similar to each other but were significantly lower than those for BDE-153, BDE-197, and BDE-209. This ratio characteristic of BDE congeners was not consistent with our result. In our study, the $\mathrm{P} / \mathrm{M}$ ratios of $\mathrm{BDE}$ congeners also differed significantly $(p<0.01$, Kruskal-Wallis $\mathrm{H}$ test), with the significantly lower ratio for BDE209 than that for BDE-28 ( $p<0.01$, Mann-Whitney $U$ test). This showed that BDE-209 remained less rather than more in the placental tissue, although its transfer was hindered more when entering the fetus (Table 1). The placental tissue was collected in 
Table 1

Fetal-maternal ratios and placental-maternal ratios of eight PBDE congeners, median, and (25th; 75 th percentile).

\begin{tabular}{lllll}
\hline Congener & $\mathrm{n}_{\text {pairs }}$ & $\mathrm{F} / \mathrm{M}$ ratio & $\mathrm{n}_{\text {pairs }}$ & $\mathrm{P} / \mathrm{M}$ ratio \\
\hline BDE-28 & 65 & $0.77(0.52-1.18)$ & 64 & $0.25(0.17-0.35)$ \\
BDE-47 & 64 & $0.84(0.60-1.51)$ & 62 & $0.18(0.10-0.30)$ \\
BDE-100 & 28 & $0.63(0.43-0.81)$ & 14 & $0.21(0.15-0.25)$ \\
BDE-99 & 57 & $0.62(0.44-1.00)$ & 44 & $0.20(0.15-0.26)$ \\
BDE-154 & 59 & $0.45(0.34-0.65)$ & 37 & $0.21(0.15-0.24)$ \\
BDE-153 & 70 & $0.41(0.29-0.54)$ & 69 & $0.18(0.12-0.23)$ \\
BDE-183 & 69 & $0.40(0.25-0.62)$ & 59 & $0.21(0.13-0.27)$ \\
BDE-209 & 35 & $0.55(0.25-0.89)$ & 55 & $0.15(0.08-0.24)$ \\
\hline
\end{tabular}

the early pregnancy, and the whole blood used in Zhao et al.'s study (2013) may partly accounting for the difference in the placental retention to $\mathrm{BDE}$ congeners in the two studies. However, it could be seen that the $\mathrm{P} / \mathrm{B}$ ratios for all BDE congeners in Zhao et al.' study (approximately $0.25-0.5)$, like our study $(0.15-0.25)$, varied in a narrow range.

Furthermore, the difference between the extent of the placental transfer ( $\mathrm{F} / \mathrm{M}$ ratio) and placental retention ( $\mathrm{P} / \mathrm{M}$ ratios) was compared by the Mann-Whitney $U$ test. The result was significant for all the eight BDE congeners $(p<0.01)$, signifying that the extent of transplacental transfer was larger than that of the placental retention.

Overall, our study indicated that the placental barriers partially hindered the transfer of PBDEs into fetus, and this hindrance was more effective for the higher-brominated BDE congeners. The extent of transplacental transfer was larger than that of placental retention. The higher-brominated BDE congener was hindered more by the placenta, but it did not tend to remain in more amounts in the placenta. This conflicting results with the published literature might be clarified by further research on the distribution mechanism of PBDEs.

\subsection{Predication of mother-placenta-fetus distribution}

Because the placenta is the intermediary linking maternal blood and cord blood, it is expected that POPs are highly correlated among maternal serum, placenta, and cord serum (Frederiksen et al., 2010). In the present study, significantly positive correlations were found for concentrations of all detectable individual compounds, except for BDE-209, among the mother- placenta-fetus system ( $p<0.05$ for each, Spearman correlation analysis). The significant correlation observed demonstrated a high degree of intercorrelation of most BDE distributions among maternal serum, placenta, and umbilical cord serum.

In the present study, the data were compared with those reported by Lv et al. (2015) and Needham et al. (2011), where the extreme concentrations were eliminated sequentially until the ratio (cord serum vs. maternal serum or placenta vs. maternal serum) was within three standard deviations from the overall average because pollutants are likely to partition in a nonequilibrium fashion in a few cases. Then, on the basis of the lipid-adjusted concentrations, the relative distribution of seven BDE congeners (BDE-209 excluded) in the maternal serum, cord serum, and placenta might be linearly fitted (using the least squares) with the following equation:

$\log (y)=n \log (x)+\log (b)$

where $x$ and $y$ are the congener concentration among tissues, and $n$ and $b$ are constants. Relative parameters on the fitted equation of the log-transformed lipid-adjusted concentrations for the maternal serum vs. cord serum and maternal serum vs. and placentas are shown in Table 3. The plots for BDE-153 are shown in Fig. 3, and the plots for other congeners are shown in Figure SI- 1 of the Supporting Information. By using these equations, we could use the concentration of individual BDE congener in maternal blood to estimate the concentration in placental tissue and/or cord blood, and to assess the prenatal exposure. However, the corresponding equation for some congeners should be considered with caution, as the small-paired placenta-maternal serum sample sizes (e.g. $\mathrm{n}=14$ for BDE-100) and the low $R^{2}$ value (e.g. 0.32 for BDE-28) between paired placenta and maternal serum.

\subsection{Correlation of PBDEs and thyroid hormone in maternal blood}

Tables SI-6 lists several studies about the relationship between PBDE exposure and $\mathrm{TH}$ levels in humans, including pregnant women and neonates/infants, general population, and pregnant women and general population related to e-waste recycling activities. As shown in Tables SI-6, the conclusions of these studies are contradictory. Some studies found no obvious relevance, while other studies indicated a significant association. Even in the studies in which an association was found, the relationships still differed. For example, Vuong et al. (2015) suggested that maternal BDE-47 exposure was associated with the increasing $\mathrm{TT}_{3}$ in the US pregnant women, while Kim et al. (2013) found the decreasing trend in Korean pregnant women. For the Californian pregnant women,

Table 2

The fetus-maternal ratio of specific BDE congeners.

\begin{tabular}{|c|c|c|c|c|c|c|c|c|c|c|}
\hline BDE-28 & BDE-47 & BDE-99 & BDE-100 & BDE-153 & BDE-154 & BDE-183 & BDE-209 & Correlation & Comment & Ref. \\
\hline \multirow[t]{3}{*}{$1.87(20)$} & $1.29(20)$ & $1.48(20)$ & $0.99(20)$ & $0.50(20)$ & $2.87(20)$ & & $2.88(20)$ & No discussion & $\begin{array}{l}\text { Cord blood at delivery and } \\
\text { maternal blood at the time of } \\
\text { the } 24 \text {-h postpartum }\end{array}$ & (Chen et al., 2013) \\
\hline & $1.1(9)$ & $0.6(6)$ & $0.9(6)$ & $0.5(12)$ & $0.5(12)$ & & & No discussion & $\begin{array}{l}\text { Maternal blood at the 20th and/ } \\
\text { or } 35 \text { th week of pregnancy and } \\
\text { cord blood at delivery }\end{array}$ & (Meijer et al., 2008) \\
\hline & $1.1(10)^{\mathrm{a}}$ & & & $0.6(10)^{\mathrm{a}}$ & & & $0.5(10)^{\mathrm{a}}$ & No correlation & $\begin{array}{l}\text { Maternal and cord blood at } \\
\text { delivery }\end{array}$ & (Jakobsson et al., 2012) \\
\hline $1.3(28)$ & $1.0(18)$ & & & $0.44(39)$ & & & & Highly correlated & $\begin{array}{l}\text { Peripheral blood when the } \\
\text { women admitted for the } \\
\text { cesarean section, and cord } \\
\text { blood at delivery }\end{array}$ & (Frederiksen et al., 2010) \\
\hline $1.26(11)$ & $0.90(40)$ & $1.20(56)$ & & $0.56(118)$ & $0.74(39)$ & & $1.60(10)$ & $\begin{array}{l}\text { Correlation only } \\
\text { for BDE-47,-154,-153 }\end{array}$ & $\begin{array}{l}\text { Maternal serum at } 12 \text { weeks of } \\
\text { pregnancy, cord serum at } \\
\text { delivery }\end{array}$ & (Vizcaino et al., 2014) \\
\hline $0.77(65)$ & $0.84(64)$ & $0.62(57)$ & $0.63(28)$ & $0.41(70)$ & $0.45(57)$ & $0.40(69)$ & $0.55(35)$ & $\begin{array}{l}\text { Correlation excluding } \\
\text { BDE-209 }\end{array}$ & $\begin{array}{l}\text { Maternal and cord blood at } \\
\text { delivery }\end{array}$ & This study \\
\hline
\end{tabular}

\footnotetext{
${ }^{\text {a }}$ Numbers of qualified pairs were 9 for BDE-47,9 for BDE-153, and 2 for BDE-209.
} 
Table 3

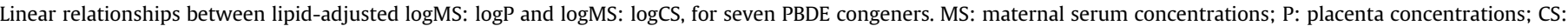
cord serum concentrations.

\begin{tabular}{|c|c|c|c|c|c|c|c|c|}
\hline Congener & $\mathrm{n}_{\text {pairs }}$ & MS vs. P & $\mathrm{R}^{2}$ & $p$-value & $\mathrm{n}_{\text {pairs }}$ & MS vs. CS & $\mathrm{R}^{2}$ & $p$-value \\
\hline BDE-28 & 60 & $\log \mathrm{P}=0.44 \log \mathrm{MS}-0.76$ & 0.32 & $<0.001$ & 60 & $\log C S=0.63 \log M S-0.20$ & 0.48 & $<0.001$ \\
\hline BDE-47 & 56 & $\log \mathrm{P}=0.85 \log \mathrm{MS}-0.71$ & 0.54 & $<0.001$ & 57 & $\log \mathrm{CS}=0.67 \log \mathrm{MS}$ & 0.58 & $<0.001$ \\
\hline BDE-100 & 14 & $\log \mathrm{P}=0.63 \log \mathrm{MS}-0.82$ & 0.70 & $<0.001$ & 27 & $\log C S=0.71 \log \mathrm{MS}-0.33$ & 0.52 & $<0.001$ \\
\hline BDE-99 & 39 & $\log \mathrm{P}=0.85 \log \mathrm{MS}-0.73$ & 0.68 & $<0.001$ & 49 & $\log C S=0.66 \log M S-0.28$ & 0.39 & $<0.001$ \\
\hline BDE-154 & 34 & $\log \mathrm{P}=0.89 \log \mathrm{MS}-0.71$ & 0.90 & $<0.001$ & 54 & $\log C S=0.76 \log M S-0.40$ & 0.71 & $<0.001$ \\
\hline BDE-153 & 65 & $\log \mathrm{P}=0.96 \log \mathrm{MS}-0.74$ & 0.88 & $<0.001$ & 62 & $\log C S=0.85 \log M S-0.35$ & 0.84 & $<0.001$ \\
\hline BDE-183 & 57 & $\log \mathrm{P}=0.88 \log \mathrm{MS}-0.68$ & 0.70 & $<0.001$ & 59 & $\log C S=0.77 \log M S-0.38$ & 0.62 & $<0.001$ \\
\hline
\end{tabular}

Chevrier et al. (2010) suggested that the total PBDE levels (including BDE-28, -47, -99, -100, and -153) were associated with a lower maternal serum TSH during pregnancy, while Zota et al. (2011) reported that the total PBDE levels (including BDE-28, -47, -99, -100 , and -153) were correlated with the increase in the TSH levels. Nevertheless, these previous studies together shed light upon the possible influence of PBDEs on TH signaling during pregnancy, and

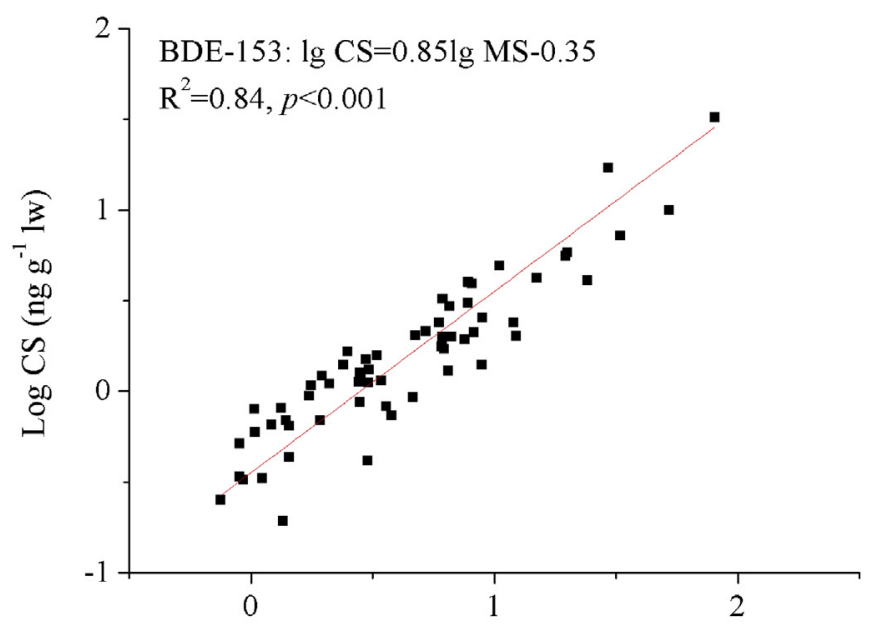

$\log \operatorname{MS}\left(\operatorname{ng~g}^{-1} \mathrm{lw}\right)$

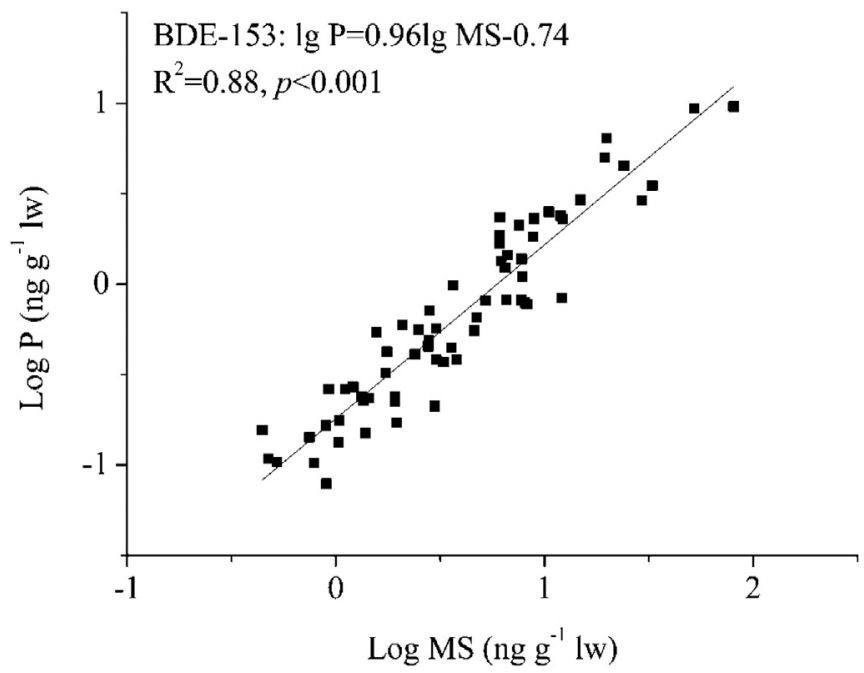

Fig. 3. Linear relationships between lipid adjusted $\log$ P: $\log$ MS and $\log$ CS: $\log$ MS for BDE-153. MS: maternal serum concentrations; P: placenta concentrations; CS: cord serum concentrations. further investigations are required to verify the actual effect because THs are critical to the health of pregnant women and child development.

In the present study, the results from the Pearson correlation analysis showed that significant correlations existed between BDE153 and the $\mathrm{TT}_{4}(r=-0.472, p=0.001)$, total $\mathrm{BDE}_{7}(\mathrm{BDE}-209$ excluded $)$, and $\mathrm{TT}_{4}(\mathrm{r}=-0.403, \mathrm{p}=0.007)$ levels in the maternal serum from the $\mathrm{R}_{20}$ group (log-transformation for all data), and a boundary correlation was found between BDE-99 and the $\mathrm{TT}_{4}$ level $(r=-0.306, p=0.054)$. After controlling for certain demographic factors including maternal age, pre-pregnancy BMI, gestational weeks, and maternal parity by a partial correlation method, the correlation remained intact between $\mathrm{BDE}-153 /$ total $\mathrm{BDE}_{7}$ and $\mathrm{TT}_{4}$ $(\mathrm{r}=-0.494, p=0.002$ for BDE-153; $\mathrm{r}=-0.455, p=0.004$ for total $\mathrm{BDE}_{7}$ ), and a significantly negative association was observed between BDE-99 and $\mathrm{TT}_{4}(\mathrm{r}=-0.365, p=0.029)$. A significant association was also found between BDE-153 and $\mathrm{TT}_{4}$ in a multiple linear regression stepwise method $(\boldsymbol{B}:-0.153,-0.227$ to -0.070 $95 \% \mathrm{Cl} ; \mathrm{R}^{2}: 0.531 ; p<0.001$ ), when abovementioned BDE levels and demographic factors were considered as independent factors.

Disruption of TH homeostasis by PBDEs in rodent studies was consistently characterized by a reduction in $\mathrm{TT}_{4}$ concentrations (Lyche et al., 2015). For wild fish from the same region (e-waste recycling area, Taizhou, China), exposure to total PBDEs (including BDE-15, -28, -47, -99, -100, -118, -153, -154, and -183) was negatively associated with $\mathrm{TT}_{4}$ (Song et al., 2012). For humans, Abdelouahab et al. (2013) reported the negative association between BDE-99/total PBDEs (including BDE-28, -47, -100, and -153) and $\mathrm{TT}_{4}$ in the maternal serum collected in the first trimester, and between BDE-99 and $\mathrm{TT}_{4}$ in the serum collected at delivery from the Canadian pregnant women. Herbstman et al. (2008) also found that BDE-153 levels in the cord serum were negatively associated with $\mathrm{TT}_{4}$ levels in the human neonatal blood spots. However, Stapleton et al. (2011) found positive relationship between BDE-99 and $\mathrm{TT}_{4}$ in the maternal serum collected at the third trimester in the US pregnant women, but the other studies found a null relationship between prenatal exposure to PBDEs and $\mathrm{TT}_{4}$ (Tables SI-6). Zhao et al. (2015) performed a meta-analysis to illustrate the complex correlation between PBDE exposure and TH serum levels in humans by reviewing 16 published articles. The meta-analysis result showed that the correlation between PBDE exposure and $\mathrm{TSH} / \mathrm{TT}_{4}$ serum levels was subjective to the median levels of PBDEs. When the median levels of PBDEs were $<30 \mathrm{ng} / \mathrm{g}$ lipid, a negative correlation existed; if the median levels of PBDEs were between 30 and $100 \mathrm{ng} / \mathrm{g}$ lipids, there was no correlation; and a positive correlation was present if the median levels of PBDEs were $>100 \mathrm{ng} / \mathrm{g}$ lipids. Our study verified the prediction on the effect of PBDEs on TT4 change in humans by Zhao et al.' study (2015). For the $\mathrm{R}_{3}$ group, no statistically significant associations were found between the maternal serum PBDEs and TH levels, even after adjusting for the demographic factors.

In our previous study, the log-transformed PBDE concentrations 
showed insignificant association with log-transformed TH levels in the women living in Wenling for more than 5 years (Lv et al., 2015). In the present study, although a significant correlation was found between PBDE level and $\mathrm{TT}_{4}$ in maternal serum in the $\mathrm{R}_{20}$ group, the association disappeared when the populations in the $R_{20}$ and $R_{3}$ groups were combined ( $p>0.05$, Pearson correlation analysis). The large difference in populations in the $R_{20}$ and the $R_{3}$ groups is related to the residential time in the e-waste recycling areas. The absence of a significant association after combining the population likely implies that the exposure duration of the study population might be one of the important factors affecting the relationship between PBDE levels and THs, as reported by Abdelouahab et al. (2013). Furthermore, some other factors might confound the outcome, including sample size, other compound levels, the methods of TH measurement, sampling time during pregnancy, and so on (Zhao et al., 2015). Therefore, more investigations on PBDEs in maternal blood/cord blood and TH in mothers/infants are needed for further studies, with a focus on the confounders in detail to obtain the explicit conclusion.

\section{Conclusions}

Our study indicated that the placenta could partially block PBDEs from mother to fetus, with a higher extent for higherbrominated congeners. The PBDE levels among maternal serumplacenta-cord serum circulation could be predicted by each other, implying that the measurement of PBDE levels in the maternal body could help determine the levels in the fetus. Exposure to PBDEs was associated with the $\mathrm{TT}_{4}$ levels in the serum of pregnant women. These results extended the information on the transplacental transfer characteristics of PBDEs, and the effect of PBDE exposure on THs, which was important to assess the health risk of PBDE exposure to in utero fetus because of the potential effect on the neurodevelopment and fertility.

\section{Acknowledgments}

This work was supported by the National Natural Science Foundation of China (21177152 and 21477157).

\section{Appendix A. Supplementary data}

Supplementary data related to this article can be found at http:// dx.doi.org/10.1016/j.chemosphere.2016.11.136.

\section{References}

Abdelouahab, N., Langlois, M.F., Lavoie, L., Corbin, F., Pasquier, J.C., Takser, L., 2013. Maternal and cord-blood thyroid hormone levels and exposure to polybrominated diphenyl ethers and polychlorinated biphenyls during early pregnancy. Am. J. Epidemiol. 178, 701-713.

Ben, Y.J., Li, X.H., Yang, Y.L., Li, L., Zheng, M.Y., Wang, W.Y., Xu, X.B., 2014. Placental transfer of dechlorane plus in mother-infant pairs in an e-waste recycling area (wenling, China). Environ. Sci. Technol. 48, 5187-5193.

Chen, A., Park, J.S., Linderholm, L., Rhee, A., Petreas, M., DeFranco, E.A., Dietrich, K.N., Ho, S.M., 2013. Hydroxylated polybrominated diphenyl ethers in paired maternal and cord sera. Environ. Sci. Technol. 47, 3902-3908.

Chevrier, J., Harley, K.G., Bradman, A., Gharbi, M., Sjodin, A., Eskenazi, B., 2010. Polybrominated diphenyl ether (PBDE) flame retardants and thyroid hormone during pregnancy. Environ. Health Persp 118, 1444-1449.

Choi, G., Kim, S., Kim, S., Kim, S., Choi, Y., Kim, H.J., Lee, J.J., Kim, S.Y., Lee, S., Moon, H.B., Choi, S., Choi, K., Park, J., 2014. Occurrences of major polybrominated diphenyl ethers (PBDEs) in maternal and fetal cord blood sera in Korea. Sci. Total Environ. 491-492, 219-226.

Czerska, M., Zielinski, M., Kaminska, J., Ligocka, D., 2013. Effects of polybrominated diphenyl ethers on thyroid hormone, neurodevelopment and fertility in rodents and humans. Int. J. Occup. Med. Environ. Health 26, 498-510.

Foster, W.G., Gregorovich, S., Morrison, K.M., Atkinson, S.A., Kubwabo, C., Stewart, B., Teo, K., 2011. Human maternal and umbilical cord blood concentrations of polybrominated diphenyl ethers. Chemosphere 84, 1301-1309.
Frederiksen, M., Thomsen, C., Froshaug, M., Vorkamp, K., Thomsen, M., Becher, G., Knudsen, L.E., 2010. Polybrominated diphenyl ethers in paired samples of maternal and umbilical cord blood plasma and associations with house dust in a Danish cohort. Int. J. Hyg. Envir. Heal 213, 233-242.

Geyer, H.J., Schramm, K.W., Darnerud, P.O., Aune, M., Feicht, E.A., Fried, K.W. Henkelmann, B., Lenoir, D., Schmid, P., McDonald, T.A., 2004. Terminal elimination half-lives of the brominated flame retardants TBBPA, HBCD, and lower brominated PBDEs in humans. Organohalogen Compd. 66, 3867-3872.

Haddow, J.E., Palomaki, G.E., Allan, W.C., Williams, J.R., Knight, G.J., Gagnon, J., O'Heir, C.E., Mitchell, M.L., Hermos, R.J., Waisbren, S.E., Faix, J.D., Klein, R.Z 1999. Maternal thyroid deficiency during pregnancy and subsequent neuropsychological development of the child. New Engl. J. Med. 341, 549-555.

Herbstman, J.B., Sjodin, A., Apelberg, B.J., Witter, F.R., Halden, R.U., Patterson, D.G., Panny, S.R., Needham, L.L., Goldman, L.R., 2008. Birth delivery mode modifies the associations between prenatal polychlorinated biphenyl (PCB) and polybrominated diphenyl ether (PBDE) and neonatal thyroid hormone levels. Environ. Health Persp. 116, 1376-1382.

Huang, F., Wen, S., Li, J., Zhong, Y., Zhao, Y., Wu, Y., 2014. The human body burden of polybrominated diphenyl ethers and their relationships with thyroid hormones in the general population in Northern China. Sci. Total Environ. 466-467, 609-615.

Jakobsson, K., Fang, J., Athanasiadou, M., Rignell-Hydbom, A., Bergman, A., 2012 Polybrominated diphenyl ethers in maternal serum, umbilical cord serum, colostrum and mature breast milk. Insights from a pilot study and the literature. Environ. Int. 47, 121-130.

Kim, U.J., Kim, M.Y., Hong, Y.H., Lee, D.H., Oh, J.E., 2012. Assessment of impact of internal exposure to PBDEs on human thyroid function-comparison between congenital hypothyroidism and normal paired blood. Environ. Sci. Technol. 46, 6261-6268.

Kim, S., Park, J., Kim, H.J., Lee, J.J., Choi, G., Choi, S., Kim, S.Y., Moon, H.B., Choi, K. 2013. Association between several persistent organic pollutants and thyroid hormone levels in serum among the pregnant women of Korea. Environ. Int. 59, 442-448.

Kim, J.T., Son, M.H., Lee, D.H., Seong, W.J., Han, S., Chang, Y.S., 2015, Partitioning behavior of heavy metals and persistent organic pollutants among fetomaternal bloods and tissues. Environ. Sci. Technol. 49, 7411-7422.

Li, L.X., Chen, L., Meng, X.Z., Chen, B.H., Chen, S.Q., Zhao, Y., Zhao, L.F., Liang, Y., Zhang, Y.H., 2013. Exposure levels of environmental endocrine disruptors in mother-newborn pairs in China and their placental transfer characteristics. PLoS One 8, e62526.

Lv, Q-X., Wang, W., Li, X.-H., Yu, L., Zhang, Y., Tian, Y., 2015. Polychlorinated biphenyls and polybrominated biphenyl ethers in adipose tissue and matched serum from an E-waste recycling area (Wenling, China). Environ. Pollut. 199, 219-226.

Lyche, J.L., Rosseland, C., Berge, G., Polder, A., 2015. Human health risk associated with brominated flame-retardants (BFRs). Environ. Int. 74, 170-180.

Meijer, L., Weiss, J., Van Velzen, M., Brouwer, A., Bergman, A., Sauerf, P.J.J., 2008. Serum concentrations of neutral and phenolic organohalogens in pregnant women and some of their infants in The Netherlands. Environ. Sci. Technol. 42, 3428-3433.

Myren, M., Mose, T., Mathiesen, L., Knudsen, L.E., 2007. The human placenta-an alternative for studying foetal exposure. Toxicol. Vitro 21, 1332-1340.

Needham, L.L., Grandjean, P., Heinzow, B., Jorgensen, P.J., Nielsen, F., Patterson, D.G., Sjodin, A., Turner, W.E., Weihe, P., 2011. Partition of environmental chemicals between maternal and fetal blood and tissues. Environ. Sci. Technol. 45, $1121-1126$.

Nyholm, J.R., Norman, A., Norrgren, L., Haglund, P., Andersson, P.L., 2008. Maternal transfer of brominated flame retardants in zebrafish (Danio rerio). Chemosphere 73, 203-208.

Phillips, Donald L., Virlyn, J.L.P., Burse, W., Bernert Jr., John T., Omar Henderson, L. Needham, Larry L., 1989. Improved determination of total serum lipids by the sulfo-phospho-vanillin reaction. Arch. Environ. Contam. Toxicol. 18, 495-500.

Song, Y., Wu, N., Tao, H., Tan, Y., Gao, M., Han, J., Shen, H., Liu, K., Lou, J., 2012 Thyroid endocrine dysregulation and erythrocyte DNA damage associated with PBDE exposure in juvenile crucian carp collected from an e-waste dismantling site in Zhejiang province, China. Environ. Toxicol. Chem. 31, 2047-2051.

Stapleton, H.M., Eagle, S., Anthopolos, R., Wolkin, A., Miranda, M.L., 2011. Associations between polybrominated diphenyl ether (PBDE) flame retardants, phenolic metabolites, and thyroid hormones during pregnancy. Environ. Health Persp. 119, 1454-1459.

Takahashi, O., Oishi, S., 2000. Disposition of orally administered 2,2-bis(4-hydroxyphenyl)propane (bisphenol A) in pregnant rats and the placental transfer to fetuses. Environ. Health Persp. 108, 931-935.

Talsness, C.E., 2008. Overview of toxicological aspects of polybrominated diphenyl ethers: a flame-retardant additive in several consumer products. Environ. Res. 108, 158-167.

Thuresson, K., Höglund, P., Hagmar, L., Sjödin, A., Bergman, Å., Jakobsson, K., 2006. Apparent half-lives of hepta- to decabrominated diphenyl ethers in human serum as determined in occupationally exposed workers. Environ. Health Persp. $114,176-181$.

Vizcaino, E., Grimalt, J.O., Fernandez-Somoano, A., Tardon, A., 2014. Transport of persistent organic pollutants across the human placenta. Environ. Int. 65, $107-115$.

Vuong, A.M., Webster, G.M., Romano, M.E., Braun, J.M., Zoeller, R.T., Hoofnagle, A.N., Sjodin, A., Yolton, K., Lanphear, B.P., Chen, A.M., 2015. Maternal polybrominated 
diphenyl ether (PBDE) exposure and thyroid hormones in maternal and cord sera: the HOME study, Cincinnati, USA. Environ. Health Persp. 123, 1079-1085.

Zhao, Y., Ruan, X., Li, Y., Yan, M., Qin, Z., 2013. Polybrominated diphenyl ethers (PBDEs) in aborted human fetuses and placental transfer during the first trimester of pregnancy. Environ. Sci. Technol. 47, 5939-5946.

Zhao, X., Wang, H., Li, J., Shan, Z., Teng, W., Teng, X., 2015. The correlation between polybrominated diphenyl ethers (PBDEs) and thyroid hormones in the general population: a meta-analysis. PLoS One 10, e0126989.

Zota, A.R., Park, J.S., Wang, Y., Petreas, M., Zoeller, R.T., Woodruff, T.J., 2011. Polybrominated diphenyl ethers, hydroxylated polybrominated diphenyl ethers, and measures of thyroid function in second trimester pregnant women in California. Environ. Sci. Technol. 45, 7896-7905. 